\title{
Prioritisation of areas for early detection of southward movement of arctic fox rabies based on historical surveillance data in Quebec, Canada
}

\section{Original Paper}

Cite this article: Aenishaenslin C, Page D, Gagnier M, Massé A, Fehlner-Gardiner C, Lambert L, Hongoh V, Tinline R (2021). Prioritisation of areas for early detection of southward movement of arctic fox rabies based on historical surveillance data in Quebec, Canada. Epidemiology and Infection 149, e20, 1-9. https://doi.org/10.1017/ S0950268820003003

Received: 4 June 2020

Revised: 13 November 2020

Accepted: 6 December 2020

\section{Key words:}

Prioritisation; public health; Rabies (animal); surveillance; zoonoses

\section{Author for correspondence:}

C. Aenishaenslin, E-mail: cecile.

aenishaenslin@umontreal.ca

\section{Aenishaenslin ${ }^{1,2}$ (D) D. Page ${ }^{1}$, M. Gagnier ${ }^{3}$, A. Massé1,3, C. Fehlner-Gardiner ${ }^{4}$, L. Lambert ${ }^{1,5}$, V. Hongoh ${ }^{1}$ and R. Tinline ${ }^{6}$}

${ }^{1}$ Groupe de recherche en épidémiologie des zoonoses et santé publique, Faculté de médecine vétérinaire, Université de Montréal, Montréal, Québec, Canada; ${ }^{2}$ Centre de recherche en santé publique, Université de Montréal et CIUSSS du Centre-Sud-de-l'île-de-Montréal, Montréal, Québec, Canada; ${ }^{3}$ Ministère des Forêts, de la Faune et des Parcs, Québec, Canada; ${ }^{4}$ Centre of Expertise for Rabies, Canadian Food Inspection Agency, Ottawa, Canada; Institut national de santé publique du Québec, Québec, Canada and ${ }^{6}$ Department of Geography, Queen's University, Kingston, Canada

\begin{abstract}
Arctic rabies virus variant (ARVV) is enzootic in Quebec (Canada) north of the 55th parallel. With climate change, increased risk of re-incursion of ARVV in more densely populated southern regions raises public and animal health concerns. The objective of this study was to prioritise geographical areas to target for an early detection of ARVV incursion south of the 55th parallel based on the historical spatio-temporal trends of reported rabies in foxes in Quebec. Descriptive analyses of fox rabies cases from 1953 to 2017 were conducted. Three periods show increases in the number of fox rabies cases in southern regions and indicate incursion from northern areas or neighbouring provinces. The available data, particularly in central and northern regions of the province, were scarce and of low spatial resolution, making it impossible to identify the path of spread with precision. Hence, we investigated the use of multiple criteria, such as historical rabies cases, human population density and red fox (Vulpes vulpes) relative abundance, to prioritise areas for enhanced surveillance. This study underscores the need to define and maintain new criteria for selecting samples to be analysed in order to detect rapidly ARVV cases outside the current enzootic area and any potential re-incursion of the virus into central and southern regions of the province.
\end{abstract}

\section{Introduction}

Rabies is a fatal illness for mammals, including humans, caused by Lyssavirus, which is usually transmitted by the saliva of an infected animal. In Quebec (Canada), the main rabies virus variants that have circulated in wildlife are the raccoon rabies virus variant, several bat-associated variants and the arctic rabies virus variant (ARVV) [1]. ARVV is enzootic in arctic fox (Vulpes lagopus) populations established north of the 55th parallel (corresponding to the northern portion of the administrative region Nord-du-Québec, also known as Nunavik) [2]. Although arctic foxes are known as the main reservoir of the virus, both the red fox (Vulpes vulpes) and the arctic fox contribute to its circulation in wildlife [3]. Arctic fox populations are rarely found south of Nunavik, whereas red fox populations are widely distributed in all regions of the province $[4,5]$. Historically, rabies epizootics in southern Quebec were attributed to movements of rabid foxes from the north, but ARVV has been mostly absent in this region since the end of the 1990s [6, 7]. Recently, researchers and professionals have raised concerns with regards to a possible re-incursion of ARVV in central and southern regions of Quebec. Indeed, climate change could impact ARVV epidemiology by altering the range of arctic foxes or by increasing the density of red foxes and the frequency of their interactions with arctic foxes in northern geographic locations [8, 9]. More frequent interactions between these two species could facilitate disease transmission and increase rabies risk both in animals and humans across the province [10].

Currently, in Quebec, surveillance of ARVV is mainly based on the analysis of domestic and wild animal specimens that are submitted to the Canadian Food Inspection Agency (CFIA) laboratory. Specimens are most often submitted following a potential exposure to rabies of a human being, in order to inform public health practices and the administration of post-exposure prophylaxis [11]. Given that this surveillance system was not designed for an early detection of ARVV cases, the overall objective of this study was to prioritise geographical areas to target for the early detection of ARVV incursion south of the 55th parallel based 
on the spatio-temporal trends of reported rabies in foxes in Quebec from 1953 to 2017 and additional criteria such as human and fox population indicators.

\section{Materials and methods}

Retrospective descriptive temporal and spatial analyses of rabies cases in arctic and red foxes in Quebec were conducted based on laboratory-confirmed animal cases identified by the Canadian Food Inspection Agency (CFIA). The CFIA database includes data on confirmed domestic and wildlife rabies cases analysed between 1926 (first case registered in the database) and 2017 (end of the study period). Rabies cases in red and arctic foxes were included in the analysis when infections with ARVV was confirmed in the database or when no variant was specified (rabies infections in foxes were then assumed to be infection with ARVV). Confirmed cases from Ontario for 1950-1963 and 1980-1988 were also provided by CFIA.

The spatial distribution of fox rabies cases during three infection waves was examined. For the purposes of this project, a wave was defined as a period of significant increase in the number of cases and affecting more than two administrative regions. To define the beginning of a wave, we used the following approach. The average annual number of cases outside an infection wave was calculated (mean $=5.4$ cases per year, standard deviation $=$ 5.2). The increase in the number of cases was calculated for each year as the difference between the number of cases in this year with the number of cases in the preceding year. When the increase in the number of cases exceeded 2 standard deviations calculated outside a wave, the year was considered as the first year of an infection wave. When the number of cases decreased to a maximum of two times the average annual number of cases outside a wave, it was considered as the end of an infection wave.

Index cases were defined as the first reported rabies cases of each wave, including cases reported the year before the start of the infection wave (year -1 ), the first year of the wave (year 0 ) and the second year of the wave (year +1$)$. Index cases were examined as an indicator of the possible geographical origin of the wave. The location of the index cases of each wave was estimated based on the municipality (when available) or regional county municipalities centroid GPS coordinates.

Following the analysis of the historic data, we used the following approach to identify the geographic areas to target for an early detection of ARVV movements. The approach consisted of five steps: (1) determination of the municipalities included for the evaluation; (2) determination of the prioritisation criteria; (3) evaluation of criteria for each municipality; (4) integration of data to delineate the priority zones and (5) sensitivity analysis.

A total of 259 municipalities were considered in the following regions for the prioritisation: Abitibi-Témiscamingue, Côte-Nord, Mauricie, Saguenay-Lac-Saint-Jean and the Eeyou Istchee Baie-James and Jamésie portions of the Nord-du-Québec (total study area $=1495246 \mathrm{~km}^{2}$; mean municipality area $=2576 \mathrm{~km}^{2}$; standard deviation $=14959 \mathrm{~km}^{2}$; Fig. 1). These regions were considered given their location at the border of the 55th parallel that delimit the geographic area considered enzootic to ARVV in Quebec. Municipality was chosen as the spatial unit of analysis given that is was the only consistent geographical unit reported in the CFIA database over time [12].

Criteria for the prioritisation of municipalities were determined in collaboration with wildlife health and public health experts from Quebec provincial authorities (Ministère des Forêts, de la Faune et des Parcs du Québec (MFFP) and Institut national de santé publique du Québec (INSPQ)). Three criteria were used for identifying municipalities to target for an early detection of ARVV which were the following: (1) ARVV risk, based on either historic fox rabies cases (index cases of each infection wave), recent ARVV cases or the proximity to Ontario or Labrador where ARVV is endemic; (2) availability of potential observers and (3) presence of animal populations that can act as the disease reservoirs (criteria description presented in Table 1).

The rationale behind the selection of these criteria and indicators was the following. For ARVV risk, index cases of each infection wave were considered given that their location may be an indicator of important corridors used by fox populations and channelling the spread of the virus. Recent cases were considered because they were located in regions where recent ARVV infections were detected. Proximity to Ontario or Labrador was also considered given that these locations may represent areas at higher risk of new incursion of ARVV in Quebec. For availability of potential observers, which were defined as local inhabitants susceptible to detect dead or strange-acting animals, the human population density was used as an indicator given that an increased probability of detection in areas of higher human density was documented in the context of raccoon rabies surveillance [13]. Finally, red fox relative abundance was considered, given that the probability of virus dissemination increases when host population density increases.

Human population density was estimated for the selected municipalities by dividing the municipal population in 2018 by the total land area of the municipality provided by the Institut de la statistique du Québec [13]. The resulting population density distribution was examined using ArcGIS and four categories were established based on the natural breaks: (1) high (204-4083 people $\left./ \mathrm{km}^{2}\right)$; (2) moderate (10-204 people $/ \mathrm{km}^{2}$ ); (3) low (1-10 people $/ \mathrm{km}^{2}$ ) and (4) very low (0-1 person $\left./ \mathrm{km}^{2}\right)$.

Red fox relative abundance was estimated using the registered traded furs (number of traded furs $/ 100 \mathrm{~km}^{2}$ ) provided by the MFFP. Traded furs are calculated by furbearer animal management units, the size of which range from 168 to $481842 \mathrm{~km}^{2}$. The resulting estimate distribution was examined using ArcGIS and four categories were established, based on MFFP categorisation [14]: (1) high (>10 trapped foxes $\left./ 100 \mathrm{~km}^{2}\right)$; (2) moderate (3-10 trapped foxes $\left./ 100 \mathrm{~km}^{2}\right)$; (3) low $(0.5-3$ trapped foxes/100 $\mathrm{km}^{2}$ ) and (4) very low (0-0.5 trapped foxes $\left./ 100 \mathrm{~km}^{2}\right)$.

Indicators for each criterion were evaluated for each municipality (Table 1). To combine criteria and delineate priority areas for an early detection of ARVV movements, each municipality was classified in one of the three priority level (priority 1, priority 2 or not prioritised). All municipalities that were considered at risk for ARVV incursions (satisfying criterion 1) were included in the priority 1 area. Municipalities with high human population density and high estimated red fox relative abundance were also included in the priority 1 area. Because of the uncertainty of the localisation of ARVV cases recorded in the CFIA database before 1985 (year of the beginning of the electronic reporting system), municipalities that were neighbouring with or enclaved by municipalities satisfying criteria 1 (ARVV risk) were also included in the priority 1 area. Municipalities that were neighbouring with or surrounded by priority 1 municipalities were defined as priority 2. Mapping was performed in ArcGIS (version 10.2; ESRI). 


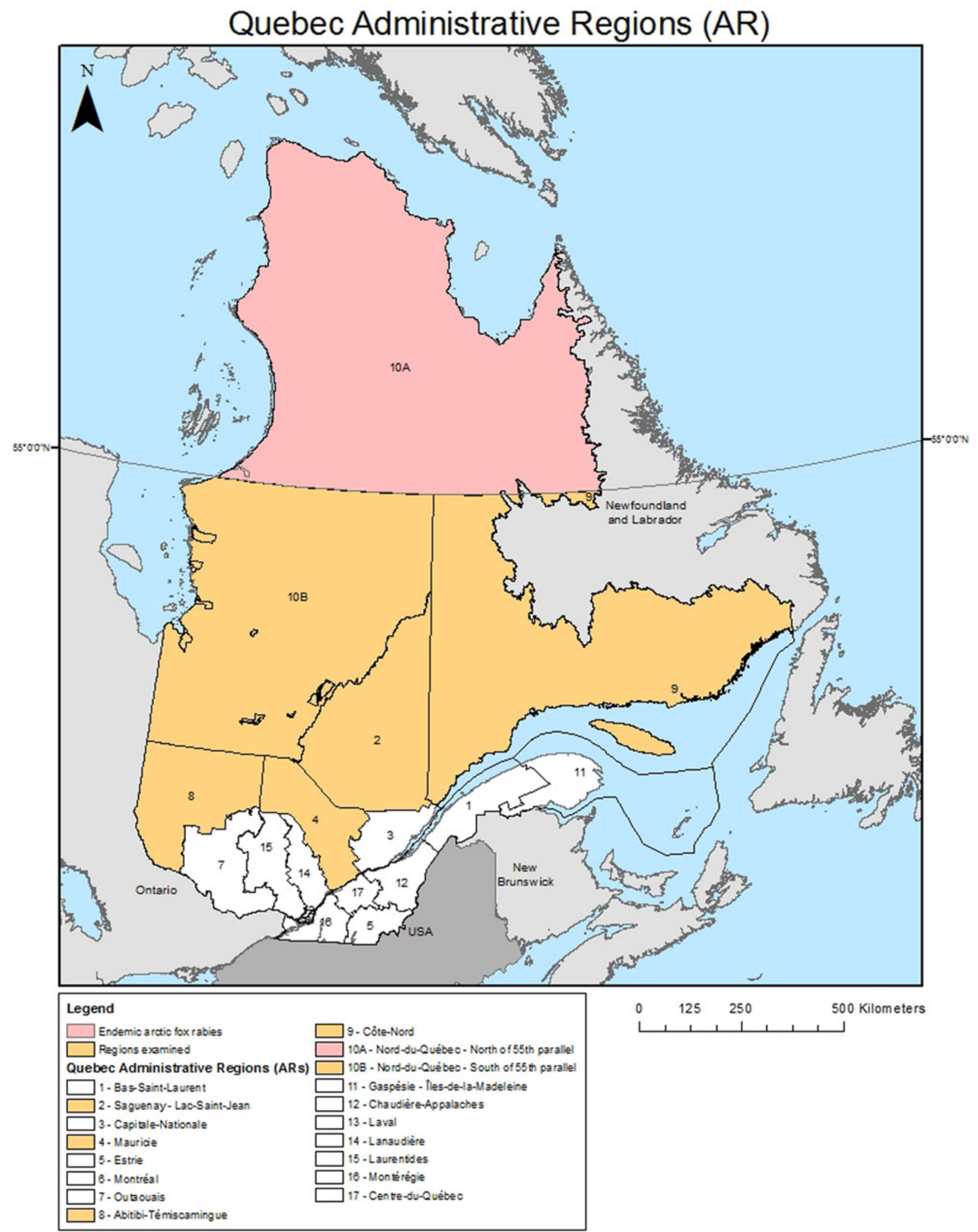

Fig. 1. Administrative regions in Quebec, Canada. 
Table 1. Number of municipalities satisfying each prioritisation criterion by administrative region (\% for the region for each criterion)

\begin{tabular}{|c|c|c|c|c|c|c|c|}
\hline & & $\begin{array}{l}\text { All } \\
\text { regions }\end{array}$ & Abitibi-Témiscamingue & Côte-Nord & Nord-du-Québec & Saguenay-Lac-Saint-Jean & Mauricie \\
\hline Criteria & Indicators & 259 & $82(32 \%)$ & $54(21 \%)$ & $14(5 \%)$ & $60(23 \%)$ & $\begin{array}{l}49 \\
(19 \%)\end{array}$ \\
\hline \multirow[t]{3}{*}{ (1) ARVV risk } & $\begin{array}{l}\text { (A) Presence of at least one fox rabies } \\
\text { case (ARVV) since } 2000 \text { reported in the } \\
\text { municipality }\end{array}$ & 12 & $6(50 \%)$ & $5(42 \%)$ & $1(8 \%)$ & 0 & 0 \\
\hline & $\begin{array}{l}\text { (B) Presence of at least one index case } \\
\text { reported during an infection wave }\end{array}$ & 3 & $2(67 \%)$ & $1(33 \%)$ & 0 & 0 & 0 \\
\hline & $\begin{array}{l}\text { (C) Municipality neighbouring A or B or } \\
\text { Ontario or Labrador where ARVV is } \\
\text { endemic }\end{array}$ & 43 & $31(72 \%)$ & $11(26 \%)$ & $1(2 \%)$ & 0 & 0 \\
\hline \multirow{2}{*}{$\begin{array}{l}\text { (2) Availability of potential } \\
\text { observers of new rabies cases in } \\
\text { wildlife }\end{array}$} & $\begin{array}{l}\text { High human population density } \\
\text { (between } 204 \text { and } 4083 \text { people } / \mathrm{km}^{2} \text { ) }\end{array}$ & 22 & $7(32 \%)$ & $8(36 \%)$ & 0 & $4(18 \%)$ & $3(14 \%)$ \\
\hline & $\begin{array}{l}\text { Moderate human population density } \\
\text { (between } 10 \text { and } 204 \text { people } / \mathrm{km}^{2} \text { ) }\end{array}$ & 73 & $12(16 \%)$ & $10(14 \%)$ & $4(5 \%)$ & $18(25 \%)$ & $\begin{array}{l}29 \\
(40 \%)\end{array}$ \\
\hline \multirow{2}{*}{$\begin{array}{l}\text { (3) Presence of animal } \\
\text { populations that can act as the } \\
\text { disease reservoirs }\end{array}$} & $\begin{array}{l}\text { High estimated red fox relative } \\
\text { abundance }\left(>10 \text { foxes } / 100 \mathrm{~km}^{2}\right)\end{array}$ & 6 & 0 & 0 & 0 & $6(100 \%)$ & 0 \\
\hline & $\begin{array}{l}\text { Moderate estimated red fox relative } \\
\text { abundance (between } 3 \text { and } 10 \text { trapped } \\
\text { foxes } / 100 \mathrm{~km}^{2} \text { ) }\end{array}$ & 61 & $10(17 \%)$ & $4(7 \%)$ & $5(9 \%)$ & $2(3 \%)$ & $\begin{array}{l}37 \\
(64 \%)\end{array}$ \\
\hline $\begin{array}{l}\text { Satisfy criterion (2, high) and ( } 3 \text {, } \\
\text { high)) }\end{array}$ & & 1 & 0 & 0 & 0 & $1(100 \%)$ & 0 \\
\hline Priority 1 area & $\begin{array}{l}\text { Municipalities satisfying criteria: (1A) or } \\
(1 \mathrm{~B}),(1 \mathrm{C}) \text {, or ( } 2 \text { and } 3)\end{array}$ & 58 & $38(66 \%)$ & $17(29 \%)$ & $2(3 \%)$ & $1(2 \%)$ & 0 \\
\hline Priority 2 area & $\begin{array}{l}\text { Municipalities bordering or enclaved by } \\
\text { priority } 1 \text { municipalities }\end{array}$ & 92 & $40(43 \%)$ & $13(14 \%)$ & 0 & $34(37 \%)$ & $5(5 \%)$ \\
\hline
\end{tabular}


Finally, sensitivity analysis was conducted in order to examine the impact of the human population density and estimated red fox relative abundance criteria on the classification of municipalities.

\section{Results}

Between 1926 and 2017, 6814 rabies cases were recorded in Quebec, Canada. Of these cases, $11.8 \%$ occurred in dogs $(n=$ 802), whereas wild canids (arctic foxes, red foxes, wolves (Canis lupus) and coyotes (Canis latrans)) represented about half $(n=$ $3368,49.4 \%)$ of all reported cases. The remaining rabies cases were reported in other species, such as bats, raccoons and livestock and are not presented in this study. Of the cases reported in wild canids, $97.4 \%$ involved foxes $(n=3282$, including 39 cases in arctic foxes and 3243 cases in red foxes). The remaining 86 cases involved wolves and coyotes. The first-recorded rabies case in a wild canid in the province occurred in 1953. Rabies cases were recorded in Nunavik (corresponding to the enzootic region north of the 55th parallel) during the entire period (1953-2017), for a total of 101 rabid foxes reported in this region, representing an annual mean of 1.6 cases/year.

Three periods show increases in the number of fox rabies cases in the province between 1953 and 2017, which also affected regions located south of the 55th parallel, suggesting epizootics in fox populations in these regions (Fig. 2).

The first infection wave occurred between 1956 and 1958. Index cases were recorded in central (Abitibi-Témiscamingue in 1955 and 1956) and southern regions (Outaouais and Montérégie in 1957) (Fig. 3A). This wave was of short duration, but rapidly reached a high number of cases in $1957(n=160$, mean annual number of cases $=64$, standard deviation $=68$; Fig. 2 ).

The second infection wave occurred from 1960 to 1979 (1230 cases, mean annual number of cases $=62$, standard deviation $=$ 39). Index cases were recorded in several regions located in central and southern Quebec (Fig. 3B). A high number of cases in foxes was observed during this period, but the increase was more gradual and remained between 11 and 145 cases annually for almost 20 years (Fig. 2).

The third wave (1986-1997, total of 1702 recorded cases; mean annual number of cases $=142$, standard deviation $=141$ ) primarily affected two southern regions of the province in 1985 (Outaouais and Montérégie) but cases were reported in central and northern regions of the province as early as 1986 (Fig. 3C). This wave included higher annual peaks of cases compared to previous infection waves, reaching 427 cases total in 1992 and more than 220 cases in certain regions (Fig. 2).

In addition to these three historical waves, 93 rabies cases were reported between 2000 and 2017 in the province in foxes $(62 / 93=$ $66.7 \%)$, dogs $(25 / 93=26.9 \%)$ and wolves $(6 / 93=0.06 \%)$. Among the 62 fox cases, $40(66.7 \%)$ were located north of the 55 th parallel in the enzootic region, and 20 from central regions located south of the enzootic region (14 in Abitibi-Témiscamingue and 6 in Côte-Nord). The last two cases were red foxes located in southern regions infected with a variant associated with Myotis bat species and the raccoon variant of the virus (CFIA, unpublished data). The retrospective analysis also allowed the observation of a persistence of cases detected in the Nord-du-Québec region during the study period.

Among the 259 municipalities included in the analysis, 12 (4.6\%) had one reported ARVV case in fox since 2000 (criterion $1 \mathrm{~A})$, three $(0.1 \%)$ had at least one index case in one of the three infection waves (criterion 1B), 43 (16.6\%) were neighbouring municipalities listed in criterion $1 \mathrm{~A}$ or $1 \mathrm{~B}$, or Ontario or Labrador where ARVV is endemic, 22 (8.5\%) had a high human population density and six (2.3\%) had a high estimated red fox relative abundance (Table 1). Only one municipality satisfied both criteria $1 \mathrm{~A}$ and $1 \mathrm{~B}$ and was located in the AbitibiTémiscamingue region. Only one municipality had both a high human density and high estimated red fox relative abundance.

In total, 58 municipalities (22.3\% of included municipalities) satisfied the priority 1 criteria for inclusion in a potential surveillance area for the early detection of ARVV south of the 55th parallel. Priority 1 municipalities cover $853417 \mathrm{~km}^{2}$, corresponding to $57.0 \%$ of the study area (Fig. 4 ). Ninety-two other municipalities were defined as priority 2 because they were neighbouring the priority 1 municipalities, or were completely surrounded by prioritised municipalities, corresponding to $35.5 \%$ of included municipalities. Priority 2 municipalities cover $215859 \mathrm{~km}^{2}$, corresponding to $14.4 \%$ of included area (Fig. 4).

Sensitivity analysis showed that using an alternative threshold for one criterion at the time (human population density or fox relative abundance) did not change significantly the number and location of prioritised municipalities. Using high and moderate human population density ( $v s$. high only) with high red fox relative abundance would have led to the inclusion of five other municipalities in priority 1 , of which three are already included in priority 2 (Table 1$)$. Using high and moderate ( $v s$. high only) red fox relative abundance with high human density would have led to the inclusion of seven additional municipalities, of which three are already prioritised (one in priority 1 and two in priority 2). Finally, using a combination of high and moderate human population density with high and moderate red fox relative abundance would have led to the inclusion of 47 municipalities, mostly located in Mauricie region, and was considered as not sufficiently discriminant for the purpose of this study (i.e. most of the municipalities considered for the study would be included in the priority zone).

\section{Discussion}

Delimiting specific areas for the early detection of rabies cases outside an enzootic zone or at the epidemic front is a key component of many enhanced rabies surveillance programmes in North America. The designation of areas for enhanced raccoon rabies surveillance have been based on various criteria such as the location of recent rabies cases, proximity to the Canada-US border, natural boundaries (e.g. Appalachian Ridge mountains and Great Lakes) and the existing oral rabies vaccination zones [15, 16]. Here, the prioritisation of areas for an early detection of ARVV outside the enzootic region was also based on multiple criteria, which included historical fox rabies cases, human population density and estimated red fox relative abundance.

The use of additional criteria was motivated by the lack of information provided by historical surveillance data. Indeed, the scarcity and inconsistency of available data in some years did not allow us to confirm the geographic origin of the second and third infection waves, nor to quantify changes in the incidence of rabies in foxes in areas located south to the 55th parallel enzootic zone. Consequently, this affected our capacity to identify with reasonable precision the most probable paths for new incursions of ARVV in central and southern Quebec. In addition, the limited availability of representative longitudinal data is a major limitation for estimating the current risk of rabies transmission to humans in different areas along the north-south axis, as it is 


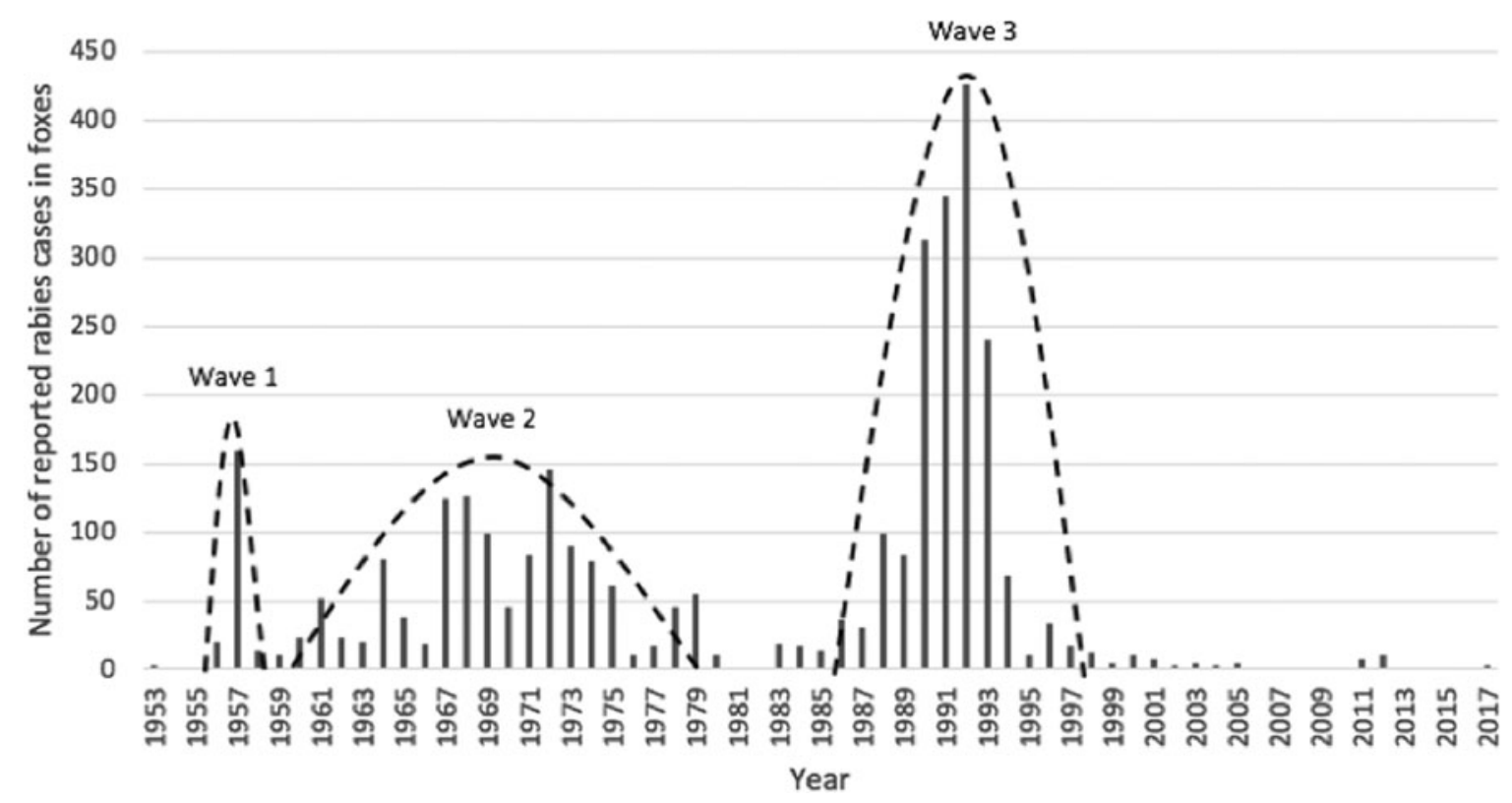

Fig. 2. Number of rabies cases in red and arctic foxes in Quebec, Canada (1953-2017). The three infection waves are illustrated with dotted lines.

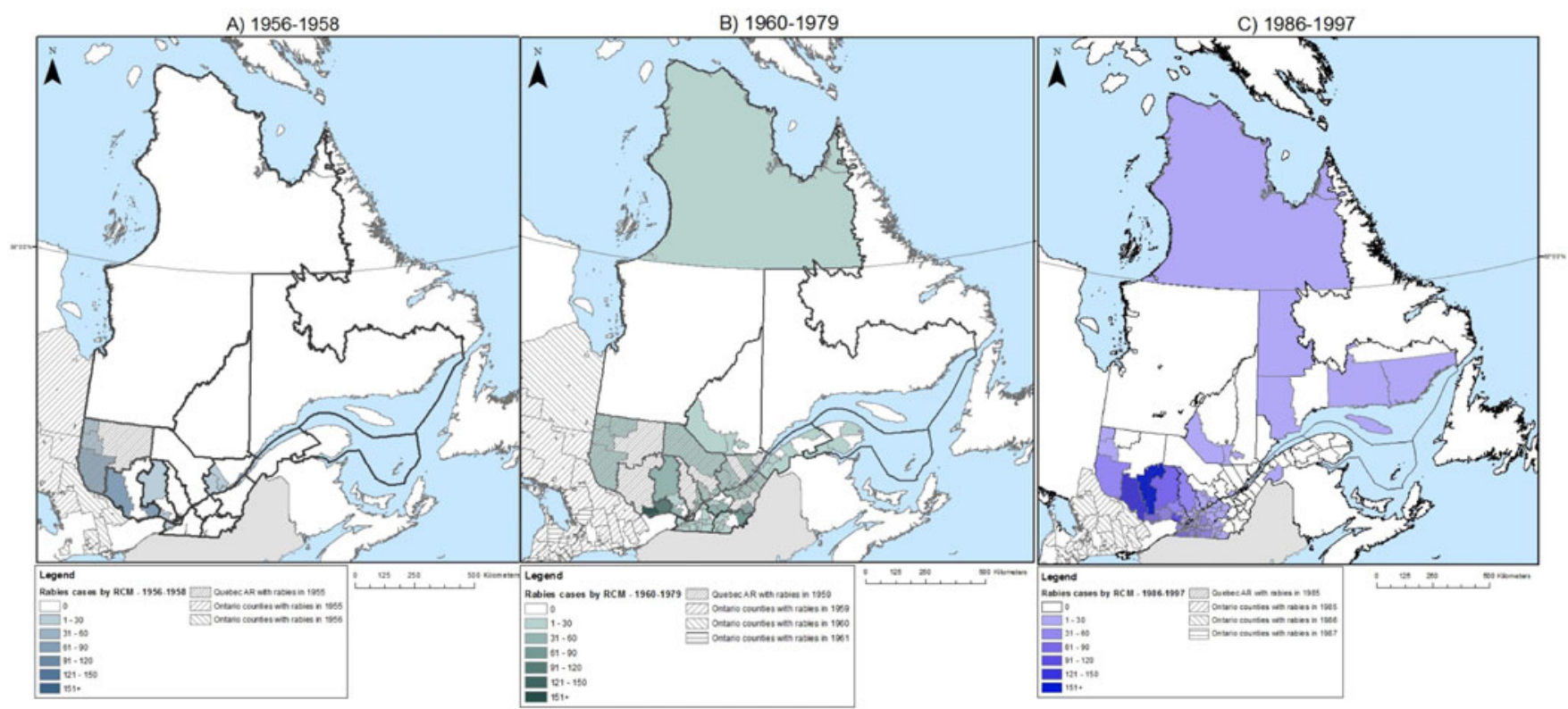

Fig. 3. Geographic locations of rabies cases in red and arctic foxes during three rabies infection waves: (A) first infection wave from 1956 to 1958 ; (B) second infection wave from 1960 to 1979 and (C) third infection wave from 1986 to 1997 in red and arctic foxes.

for predicting the evolution of this risk in a context of climate change [17].

Two main reasons explain the scarcity of passive surveillance data for arctic fox rabies in Quebec, and these are applicable as well at the Canadian level. First, the objective of the current rabies surveillance system is to guide the administration of postexposure prophylaxis of individuals who have been potentially exposed to the rabies virus. Suspect animals (dead or live animals with abnormal behaviour or neurological signs) that are reported by observers but that did not have any significant contact with humans are not usually submitted for rabies testing. Second, northern and central regions of the province represent a large territory where human populations are low and sparsely distributed [13], and consequently the lack of potential observers reduces chances of detection and reporting of fox rabies cases over wide areas. Moreover, as there is no current useful measure of fox abundance (as discussed further), which varies in time and space [18], the number of ARVV cases reported by the current system may not be a good indicator of the incidence of rabies in fox populations in the area.

Studies in southern Quebec and the USA have demonstrated that samples collected through enhanced surveillance programmes have proven useful in monitoring raccoon rabies $[15,16,19,20]$. In addition, the nature of the sample has been found to be an 


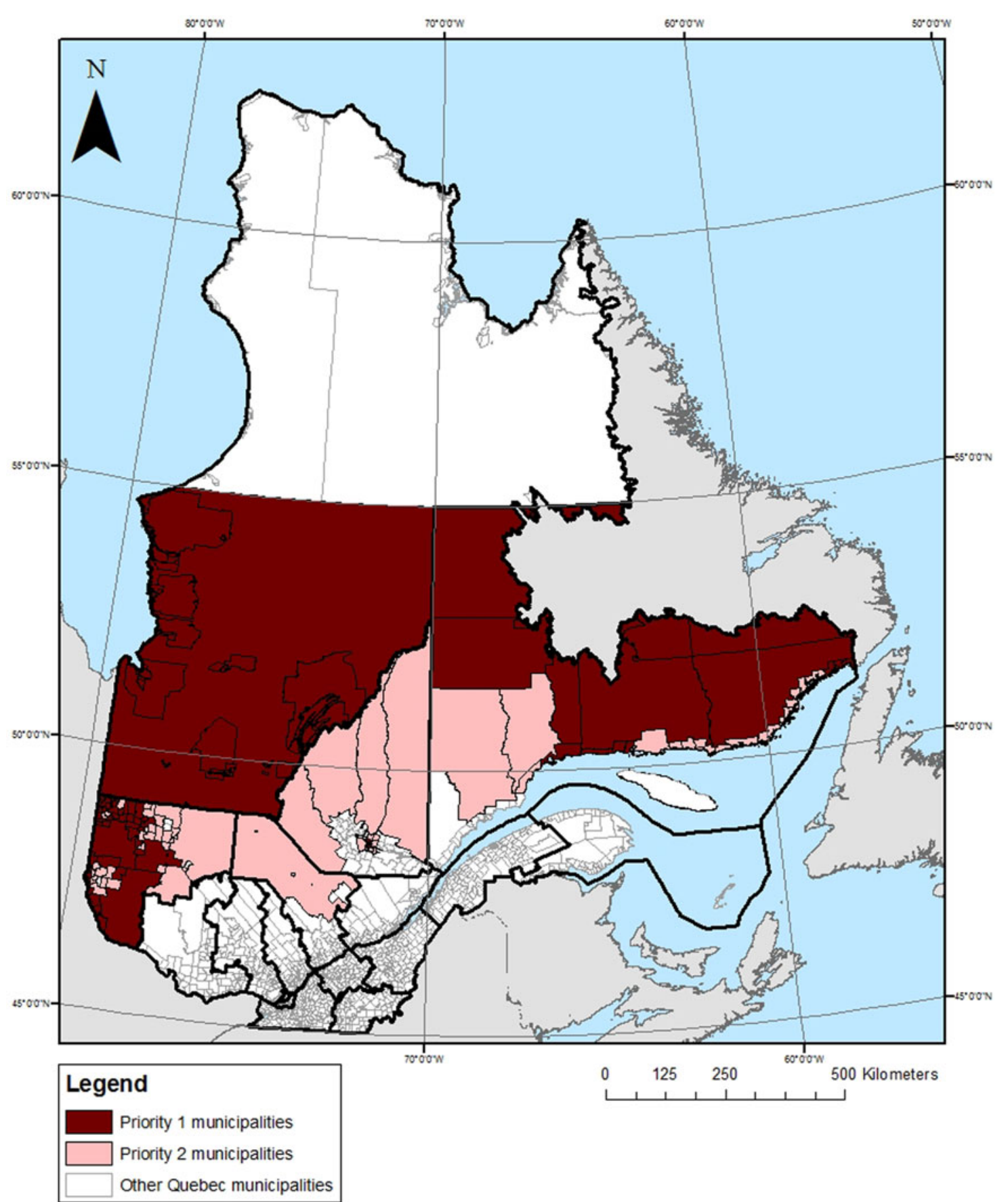

Fig. 4. Prioritised areas for early detection of southward movement of arctic fox rabies.

important factor that affects its usefulness for rabies detection [15]. For example, strange acting and animals found dead, along with public health samples, have proven to be a good source of information to monitor raccoon rabies when present $[15,20,21,22]$. The development of a system aiming for an early detection of a potential incursion of ARVV in central and southern regions of Quebec would involve testing a larger number of animals in regions prioritised through this study. Such a programme would not replace the current rabies surveillance for medical care, but would give complementary information that could serve to advise future rabies management decisions.
Given the large area to cover and the rarity of observers, the development of a new programme should first include studying the best approaches required to maximise the surveillance system's sensitivity (i.e. the probability of detecting a rabies case when present), as well as their associated costs. A first step could include collecting and testing strange acting and dead canids reported by local residents of priority 1 area. Then, data could be examined in order to identify which types of specimens would provide the best information for an early detection of ARVV incursions [23]. In addition, more research is needed to better understand characteristics of and barriers to fox 
movements in the north-south axis in order to identify the most probable corridors that would be used for these southward movements [23]. This would allow us to reduce the prioritised area for surveillance and to optimise the cost-benefits of the programme.

Our findings also corroborate observations from previous studies regarding a probable first incursion of fox rabies from northern Quebec in the 1950s $[6,7,11,24]$. First-recorded cases detected in 1953 and 1954 support the hypothesis of a movement from the north of the province, following the Hudson Bay and James Bay shores. Tabel et al. have reported fox rabies cases in villages located in northern Quebec in 1951 and suggested earlier movement from Baffin Island, although these cases are not recorded in the CFIA database [7]. The second and third waves seem less likely to have been caused by arctic fox rabies spreading directly from north of the 55th parallel, but rather by the expansion of rabies cases already present in central and southern regions during the first wave, and by an overflow of fox rabies from the neighbouring province of Ontario $[6,11]$. In the years preceding the third wave, Ontario reported a record number of fox rabies cases ( $>3000$ cases) and previous studies also suggested that this epizootic in Ontario crossed the Ottawa River Valley towards the province of Quebec during the same period [11]. Control operations, including oral vaccination, targeting fox rabies conducted in Ontario and Quebec in the 1990s contributed to the end of this infection wave and the elimination of fox rabies in southern Quebec [6,11].

The 20 most recent ARVV cases in foxes detected south of the enzootic region are of interest since they probably indicate spread from the enzootic zone. Although rabies subsequently did not persist in the affected areas, these cases suggest that such incursion from the north remains a threat. In a context where climate change could increase movements of foxes along a north-south axis, these cases highlight the need for an early detection of ARVV south of the 55th parallel before a new epizootic reaches more densely populated regions in southern Quebec.

Our findings reiterate that the enzootic Nord-du-Québec region, with the majority of recent canid rabies cases, is the region where current public health concerns are the highest [2]. However, implementing preventive and control interventions for ARVV in the North is challenging. The oral vaccination of foxes against rabies, a proven control method in southern Quebec [11], would be difficult, costly and possibly ineffective due to the sparse fox populations, the large area requiring treatment and uncertainty concerning vaccine-bait performance in arctic conditions [3].

This study has limitations. The criteria used to delineate the priority zone were considered with the same importance in the prioritisation process, given the lack of evidence on the most important factors to consider for early detection of ARVV in wildlife. However, the importance of these criteria may differ in reality. In this study, we used three criteria but had no way of weighting these criteria according their relative importance for the prioritisation. Multi-criteria decision analysis methods have been used to select geographical areas to target for surveillance, prevention and control of other zoonotic or vector-borne diseases and could constitute an interesting approach once new information is available [25].

In addition, historical surveillance data on ARVV cases in neighbouring provinces were not examined for this study and represents one of its limitations. Although the presence or absence of rabies cases in Ontario was included to better interpret the three infection waves highlighted by this study, a deeper analysis of historical rabies cases in neighbouring Ontario, Nunavut and
Labrador would be useful. For example, ARVV was found in dogs and red foxes in 2000-2001 northwest of North Bay, Ontario, and in 2013 in Kashechewan, Ontario on the James Bay coast [27]. These observations underscore the importance of transboundary collaboration for the surveillance, prevention and control of rabies, as animal movements (natural or anthropogenic such as translocation) across provinces and/or countries can constitute an important risk of introduction or reintroduction of the disease [28].

Furthermore, using the registered traded furs to categorise red fox relative abundance is not perfect, but these data were the only available for this study. Unfortunately, the validity of this database as an indicator of red fox abundance in Quebec is unknown. Traded furs are recorded for management units which vary in size, and trapping efforts may vary with changes in fur value over time, with changes in access to territories, and with changes in cultural attitudes to trapping. Moreover, tanners may not declare all furs that are collected. In this study, the high estimated red fox relative abundance was not found to be an important discriminant criterion in the prioritisation analysis, with only six municipalities (out of 259) satisfying this criterion, and of these, only one had a high human density, which led to its inclusion to the priority 1 area. Moreover, the sensitivity analysis supports the low contribution of this criterion in determining areas for the early detection of ARVV. The validation of this index or the inclusion of more accurate estimates of red fox relative abundance obtained with other methods may provide more information to include if data were available [26].

More research is needed to better evaluate the current risk of re-incursion of ARVV in central and southern regions of the province. As a first step, this study has prioritised geographic areas for enhanced surveillance of ARVV in Quebec, by combining historical surveillance data with human population densities and examining the use of fur-trapping records as a measure of relative abundance of fox populations. This study also highlights the concerns about working with inconsistent data throughout space and time, and underlines the need to develop and maintain criteria and procedures for sample collection and analyses for an early detection of a potential spread of ARVV from the north into central and southern regions of the province.

Acknowledgements. The authors would like to acknowledge Audrey Simon, Erin Rees and Agathe Allibert for insights into current arctic fox rabies research, Beverly Stevenson and Tore Buchanan from the Ontario Ministry of Natural Resources and Forestry, Susan Nadin-Davis from the Centre of Expertise for Rabies (CFIA) and Patrick Leighton and Isabelle Picard from the Quebec Rabies Scientific Committee.

Financial support. This work was supported by the Ministère des Forêts, de la Faune et des Parcs du Québec.

Conflict of interest. None.

Data availability statement. The data that support the findings of this study are available from the Canadian Food Inspection Agency (CFIA). Restrictions apply to the availability of these data, which were used with the permission of CFIA for this study.

\section{References}

1. Webster WA, Casey GA and Charlton KM (1986) Major antigenic groups of rabies virus in Canada determined by anti-nucleocapsid monoclonal antibodies. Comparative Immunology, Microbiology and Infectious Diseases 9, 59-69. 
2. Aenishaenslin C et al. (2014) Characterizing rabies epidemiology in remote Inuit communities in Québec, Canada: a 'One Health' approach. Ecohealth 11, 343-355.

3. Mørk T and Prestrud P (2004) Arctic rabies-a review. Acta Veterinaria Scandinavia 45, 1-9.

4. Berteaux D et al. (2017) Foreword to supplement 1: research on a polar species-the Arctic fox. Polar Research 36, 1.

5. Larivière S and Pasitschniak-Arts M (1996) Vulpes vulpes. Mammalian Species 537, 1-11.

6. Lagacé F (1998) Historique de la rage au Québec de 1958 à 1997. Le Médecin Vétérinaire du Québec 28, 106-110.

7. Tabel H et al. (1974) History and epizootiology of rabies in Canada. Canadian Veterinary Journal 15, 271-281.

8. Huettmann F, Magnuson EE and Hueffer K (2017) Ecological niche modeling of rabies in the changing Arctic of Alaska. Acta Veterinaria Scandinavia 59, 18.

9. Kim BI et al. (2014) A conceptual model for the impact of climate change on fox rabies in Alaska, 1980-2010. Zoonoses and Public Health 61, 72-80.

10. Simon A, Bélanger D and Leighton PA (2019) La Rage Dans les Populations de Renards au Nord du 55e Parallèle et les Effets Potentiels des Changements Climatiques. Sainte-Foy, Quebec, Canada: Institut national de santé publique du Québec; Available at (http://public.eblib. com/choice/publicfullrecord.aspx? $\mathrm{p}=3295636)$. Accessed 16 October 2019.

11. Bélanger D et al. (2020) Québec. In Gregory D \& Tinline R, (eds.), Taking the Bite out of Rabies: The Evolution of Rabies Management in Canada. Toronto: University of Toronto Press, pp. 157-178.

12. Muldoon F, Gregory DJ and Tinline R (2020) Passive surveillance. In Gregory D \& Tinline R, (eds.), Taking the Bite out of Rabies: The Evolution of Rabies Management in Canada. Toronto: University of Toronto Press, pp. 157-178.

13. Institut de la statistique du Québec. Profils statistiques par région et MRC Available at http://www.stat.gouv.qc.ca/statistiques/profils/region_00/ region_00.htm. Accessed 16 October 2019.

14. Ministère des Forêts, de la Faune et des Parcs du Québec. Provincial fur-bearing animal harvest status reports 2014-2015, Québec Available at https://mffp.gouv.qc.ca/the-wildlife/hunting-fishing-trapping/provincialfur-bearing-animal-harvest-status-reports-2014-2015/?lang=en. Accessed 11 November 2020.
15. Rees EE et al. (2011) Targeted surveillance of raccoon rabies in Québec, Canada. The Journal of Wildlife Management 75, 1406-1416.

16. Kirby JD et al. (2017) Enhanced rabies surveillance to support effective oral rabies vaccination of raccoons in the Eastern United States. Tropical Medicine and Infectious Diseases 2, 34.

17. Mills JN, Gage KL and Khan AS (2010) Potential influence of climate change on vector-borne and zoonotic diseases: a review and proposed research plan. Environmental Health Perspective 118, 1507-1514.

18. Cavallini P (1996) Variation in the social system of the red fox. Ethology Ecology \& Evolution 8, 323-342.

19. Davis AJ et al. (2019) Not all surveillance data are created equal - a multimethod dynamic occupancy approach to determine rabies elimination from wildlife. Journal of Applied Ecology 56, 2551-2561.

20. Davis AJ et al. (2019) Rabies surveillance identifies potential risk corridors and enables management evaluation. Viruses 11, 1-13.

21. Government of Ontario. Rabies in wildlife, Ontario.ca, Available at https:// www.ontario.ca/page/rabies-wildlife\#section-6. Accessed 16 October 2019.

22. Pieracci EG et al. (2020) Evaluation of rabies virus characterization to enhance early detection of important rabies epizootic events in the United States. Journal of American Veterinary Medical Association 256, 66-76.

23. Panzacchi M et al. (2016) Predicting the continuum between corridors and barriers to animal movements using step selection functions and randomized shortest paths. Journal of Animal Ecology 85, 32-42.

24. Plummer PJG (1954) Rabies in Canada, with special reference to wildlife reservoirs. Bulletin of the World Health Organization 10, 767-774.

25. Hongoh V et al. (2011) Spatially explicit multi-criteria decision analysis for managing vector-borne diseases. International Journal of Health Geographics 10, 70.

26. Gompper ME et al. (2006) A comparison of noninvasive techniques to survey carnivore communities in Northeastern North America. Wildlife Society Bulletin 34, 1142-1151.

27. CFIA. Rabies in Canada Available at https://www.inspection.gc.ca/animalhealth/terrestrial-animals/diseases/reportable/rabies/rabies-in-canada/eng/ 1356156989919/1356157139999. Accessed 16 October 2019.

28. Filejski C (2016) The changing face of rabies in Canada. Canadian Communicable Disease Report 42, 118-120. 